\title{
Pulse flow of liquid in flexible tube
}

\author{
Roman Klas ${ }^{1, *}$ and Simona Fialová ${ }^{1}$ \\ ${ }^{1}$ Brno University of Technology, Faculty of Mechanical Engineering, Victor Kaplan Department of Fluids Engineering, Technická 2 , \\ 61669 Brno, Czech Republic
}

\begin{abstract}
The simulation of liquid flow in significantly deformed elastic material is one of the more challenging tasks. Tube wall motion prediction implemented directly into CFD software can noticeably reduce the computational and time demands of such problems. The FSI simulation of a liquid-flowed flexible plastic tube was analyzed on the FEA and CFD solvers coupling basis. The flexible tube is the basic symmetric test body that could be appropriately tested on the experimental stand. A comparison of experimental data and FSI problem using commercial code and one-dimensional tube models was made by evaluating the tube wall deformation magnitudes at defined flow ratios. The type of tube material, which can be understood as a nonlinear from the stress and deformation point of view, was considered. The paper shows several possibilities of tube modeling using the main constitutive relations of linear and nonlinear mechanics. The hyperelastic material models such as neo-Hookean and Mooney-Rivlin were tested. The results represent differences in impacts on the tube liquid flow and differences in the magnitudes of the wall tube deformations. Based on these findings it should be possible to simulate the problems of liquid flow in more complicated shape flow zones, such as arteries affected by various defects, in our future research.
\end{abstract}

\section{Introduction}

In the following work, the case of fluid flow in the flexible tube will be analyzed. The main tools for assessing this task were CFD simulation of fluid flow and structural simulation of elastic wall deformation (FSI), onedimensional mathematical models of flexible pipeline and experimental data. From the analysis of the elastic tube behavior it is possible to experimentally determine the deformation of the pipe wall at the defined points and, of course, to trace the corresponding hydraulic variables such as flow and pressure. A similar case of deformation of the elastic wall due to the action of fluid occurs, for example, in the blood flow through the artery or the aorta [1-4]. Permanent or destructive deformation of the aortic, of course, has a significant impact on human health and life. For this reason, it is advantageous to study the abovementioned models. The model situation can predict fluid flow in the true aorta or its replacement.

A major complication is the fact that numerical FSI simulations are quite time consuming. Also, for all possible cases, it is not always realistic to carry out experimental measurements. Therefore, it is possible to try to simplify FSI's role by, for example, the prescribed movement of a flexible wall in simple CFD simulations, or to use simpler mathematical models. Another unfavorable fact is the nonlinear behavior of the tube wall material with respect to stress dependence and wall deformation. Therefore, the following study should be supplemented by at least a brief overview of basic nonlinear materials.

\section{FEA and CFD methods and description of the tube}

ANSYS Mechanical and ANSYS Fluent 18.2 were used as software for FSI simulation. The simulation was realized in coupling mode. The flexible wall geometry, fluid tube, and computational mesh were created in ANSYS DesignModeler and ANSYS Meshing software. Due to time-consuming FSI simulations, the number of computational cells was reduced by considering only one quarter of the tube.

Table 1. Description of numerical model.

\begin{tabular}{|c|c|c|}
\hline Reynolds number & \multicolumn{2}{|c|}{$\sim 30000, \sim 2000$} \\
\hline $\begin{array}{l}\text { Tube diameter } \\
\text { Wall thickness } \\
\text { Tube length } \\
\text { Material constants }\end{array}$ & \multicolumn{2}{|c|}{$\begin{array}{c}\mathrm{d}_{0}=12.7 \mathrm{~mm} \\
\mathrm{~s}_{0}=1.6 \mathrm{~mm} \\
\mathrm{~L}=0.5 \mathrm{~m} \\
\mathrm{E}=4 \mathrm{MPa} \\
v=0.5 \\
\mathrm{C}_{12}=650000 \mathrm{~Pa} \\
\mathrm{C}_{1}=600000 \mathrm{~Pa}, \mathrm{C}_{2}=50000 \mathrm{~Pa}\end{array}$} \\
\hline \multirow{2}{*}{$\begin{array}{l}\text { Number of } \\
\text { computational } \\
\text { cells }\end{array}$} & FEM & CFD \\
\hline & 25200 & $\sim 156000$ \\
\hline Material & neo-Hookean & water liquid \\
\hline $\begin{array}{l}\text { Turbulence model } \\
\text { and near wall } \\
\text { modeling }\end{array}$ & \multicolumn{2}{|c|}{$\begin{array}{l}\text { realizable } \mathrm{k}-\varepsilon \\
\text { enhanced wall treatment }\end{array}$} \\
\hline
\end{tabular}

\footnotetext{
* Corresponding author: klas@fme.vutbr.cz
} 


\begin{tabular}{|l|l|l|}
\hline \multirow{2}{*}{$\begin{array}{l}\text { Boundary } \\
\text { conditions }\end{array}$} & FEM & CFD \\
\cline { 2 - 3 } & $\begin{array}{l}\text { frictionless } \\
\text { fixed } \\
\text { fluid solid } \\
\text { interface }\end{array}$ & $\begin{array}{l}\text { Inlet: velocity } \\
\text { inlet, pressure } \\
\text { inlet } \\
\text { Outlet: pressure } \\
\text { outlet }\end{array}$ \\
\hline Calculation mode & $\begin{array}{l}\text { unsteady, incompressible flow, } \\
\text { incompressible solid }\end{array}$ \\
\hline
\end{tabular}

The unsteady boundary conditions based on experimental measurements were considered in the CFD analysis. The number of iterations of CFD simulation within one time step was slightly reduced with respect to the time consuming FSI analysis.

\section{One-dimensional tube model}

As it was mentioned above, the flexible tube is generally characterized by a non-linear dependence of a shear stress and deformation. This can complicate the simulation of pulsatile fluid flow through the tube. However, it will be interesting to see how significantly the non-linear properties of the tube material actually occur. For this reason, a standard Hookean material, non-linear neoHooken [5-7] and Mooney-Rivlin [8,9] materials will be included in one-dimensional models. In case of Hookean material and shear stress in the tube, we also need to consider whether it is a thin-walled or thick-walled cylinder. For thin-walled cylinders, some definitions can be partially simplified.

The continuity equation and the equation of motion represent the second part of the one-dimensional model that will describe the fluid flow through an elastic tube. Both equations will be written in a general form so that the equations are valid for all types of materials. Following must be considered in terms of some onedimensional models: whether the properties of the system represented by inertial forces, hydraulic resistances and compressibility of the fluid and the tube wall concentrate on the selected points, or if their properties continuously decompose along the tube length. For comparison, both cases will be presented. However, Tab. 2 with the list of symbols that are used in the following equations will be listed first.

Table 2. List of symbols.

\begin{tabular}{|c|l|}
\hline $\mathrm{c}$ & speed of sound \\
\hline $\mathrm{C}$ & hydraulic capacity \\
\hline $\mathrm{C}^{*}$ & unsteady friction coefficient \\
\hline $\mathrm{C}_{12}, \mathrm{C}_{1}, \mathrm{C}_{2}$ & $\begin{array}{l}\text { neo-Hookean and Mooney-Rivlin } \\
\text { material constants }\end{array}$ \\
\hline $\mathrm{d}_{0}, \mathrm{~d}, \mathrm{D}$ & inner diameter of the thin-walled tube \\
\hline $\mathrm{d}_{2}$ & outer diameter of the thick walled tube \\
\hline $\mathrm{E}$ & Young's modulus of the tube material \\
\hline $\mathrm{f}_{\mathrm{q}}, \mathrm{f}_{\mathrm{qu}}$ & $\begin{array}{l}\text { hydraulic steady and unsteady friction } \\
\text { factor }\end{array}$ \\
\hline $\mathrm{g}$ & gravitational acceleration \\
\hline $\mathrm{H}$ & hydraulic induction \\
\hline
\end{tabular}

\begin{tabular}{|c|c|}
\hline $\mathrm{K}, \mathrm{Kc}$ & $\begin{array}{l}\text { bulk modulus and corrected bulk } \\
\text { modulus }\end{array}$ \\
\hline $\mathrm{L}$ & tube length \\
\hline $\mathrm{p}_{\mathrm{I}}, \mathrm{p}_{\mathrm{II}}, \mathrm{p}_{1}, \mathrm{p}_{2}$ & $\begin{array}{l}\text { static pressure inlet and outlet, inner } \\
\text { and outer static pressure }\end{array}$ \\
\hline $\begin{array}{l}\text { Q, Qo, } \\
\text { Qc,Qv }\end{array}$ & volumetric flow rate \\
\hline $\mathrm{r}_{0}, \mathrm{r}_{10}, \mathrm{r}_{20}$ & $\begin{array}{l}\text { radii of the unloaded thin-walled and } \\
\text { thick-walled tubes }\end{array}$ \\
\hline $\mathrm{r}, \mathrm{r}_{1}, \mathrm{r}_{2}$ & $\begin{array}{l}\text { inner radius of the thin-walled tube, } \\
\text { inner and outer radius of the thick- } \\
\text { walled tube }\end{array}$ \\
\hline $\mathrm{R}$ & hydraulic resistance of the tube \\
\hline So, s & $\begin{array}{l}\text { wall thickness of the unloaded and } \\
\text { loaded tube }\end{array}$ \\
\hline $\mathrm{S}$ & variable cross-section of the tube \\
\hline $\mathrm{t}$ & time \\
\hline $\mathrm{u}_{\mathrm{a}}, \mathrm{u}_{1}, \mathrm{u}_{2}$ & $\begin{array}{l}\text { axial displacement and radial } \\
\text { displacement at the inner and outer } \\
\text { surface of the tube }\end{array}$ \\
\hline $\mathrm{v}$ & absolute velocity \\
\hline $\mathrm{V}$ & tube volume \\
\hline $\mathrm{x}$ & $\mathrm{x}$-coordinate, axis of the tube \\
\hline$\varepsilon, \varepsilon_{\mathrm{a}}, \varepsilon_{\mathrm{r}}, \varepsilon_{\mathrm{t}}$ & $\begin{array}{l}\text { engineering strain, axial, radial and } \\
\text { circumferential strain }\end{array}$ \\
\hline$\lambda, \lambda_{\mathrm{a}}, \lambda_{\mathrm{r}}, \lambda_{\mathrm{t}}$ & $\begin{array}{l}\text { stretch ratio, axial, radial and } \\
\text { circumferential stretch ratio }\end{array}$ \\
\hline$v$ & Poisson's ratio \\
\hline$\Pi_{\mathrm{ji}}$ & strain rate tensor \\
\hline$\rho$ & fluid density \\
\hline$\sigma_{\mathrm{a}}, \sigma_{\mathrm{r}}, \sigma_{\mathrm{t}}$ & axial, radial and circumferential stress \\
\hline
\end{tabular}

\subsection{Equation of motion and continuity equation}

Figure 1. represents the simplest circuit to create a onedimensional tube model. By using an electric analogy $[10,11]$, the properties of the tube are concentrated to the capacity $C$, the hydraulic resistance $R$ and the induction $H$. The position and number of $C, R$ and $H$ depend, of course, on the wavelengths.

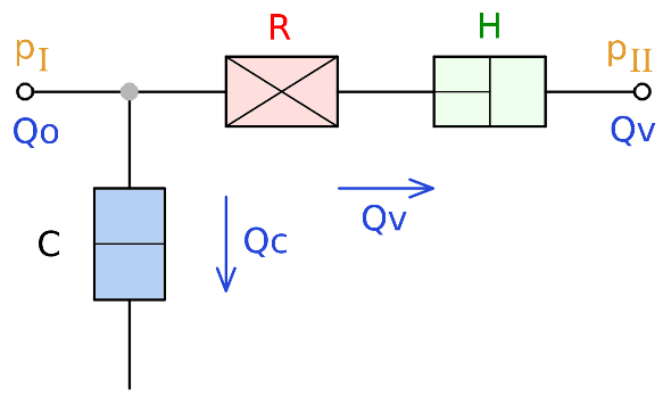

Fig. 1. Electric analogy, L - segment.

Kirchhoff's laws can be used to define the flow rate and the static pressure in equations (1) and (2).

$$
p_{I}-p_{I I}=R Q_{V}{ }^{2}+H \frac{d Q_{V}}{d t}
$$




$$
Q_{0}=Q_{V}+C \frac{d p_{I}}{d t}
$$

Capacity $C$ includes a corrected bulk modulus that describes the influence of the fluid compressibility and the tube wall flexibility (3). Of course, the $K c$ formulation is subject to a description of the stress and deformation of the tube. The definition of $H$ and $R$ corresponds to common procedures.

$$
C=\frac{V}{K_{C}}
$$

From the Navier-Stokes equations (4), the DarcyWeisbach equation and the continuity equation (5) for the compressible fluid and the bulk modulus more precise relationships for determining the flow rate and static pressure in the vertical tube can be obtained.

$$
\begin{gathered}
\rho\left(\frac{\partial v_{i}}{\partial t}+\frac{\partial v_{i}}{\partial x_{j}} v_{j}\right)=\rho g_{i}-\frac{\partial p}{\partial x_{i}}+\frac{\partial \Pi_{j i}}{\partial x_{j}} \\
\frac{\partial \rho}{\partial t}+\frac{\partial \rho v_{j}}{\partial x_{j}}=0
\end{gathered}
$$

If we consider all the variables in the equations, besides $f_{q}$ and $g$, as a function of the x-coordinate and time, we can obtain an equation of motion (6) and a continuity equation (7) that neglects convective terms. Both equations consider the variable inner radius of tube $r$. For now, we will assume that convective terms in the (6) and (7), or in (8), will be negligible.

$$
\begin{gathered}
\frac{\partial Q}{\partial t}=\frac{2 Q}{r} \frac{\partial r}{\partial t}+\frac{S}{\rho}\left(\rho g-\frac{\partial p_{1}}{\partial x}-\rho \frac{f_{q}}{2 r} \frac{Q Q}{2 S^{2}}\right) \\
\frac{\partial p_{1}}{\partial t}=-K_{C} \frac{1}{S}\left(\frac{\partial Q}{\partial x}\right)
\end{gathered}
$$

The corrected bulk modulus $K c$ in (7) includes the influence of fluid compressibility and tube deformations [12]. Using basic water hammer equations of motion, modulus $K c$ must be generally defined according to (8).

$$
K_{C}=\frac{K}{1+\frac{2 K}{r}\left(\frac{\partial p_{1}}{\partial r}\right)^{-1}}
$$

\subsection{Basic stress equations and constitutive laws}

The wall of the test tube is relatively thin and its material is hyperelastic. The brand name of tube material is named Tygon. In terms of the definition of the following relationships, it will be important to mark the dimensions, deformations and stresses in the tube (Fig. 2, 3).

Figure 3. describes two possible approaches to the tube type and the tube is defined as an open thick-walled or thin-walled rotating body. The body is also rotationally symmetric to the pressures on the inner and outer surfaces. In our case, the external pressure $p_{2}$ corresponds to the atmospheric pressure. However, it is preferable to consider the external pressure for thick-walled and thinwalled bodies as zero and internal pressure $p_{1}$ as relative. Figure 2. therefore shows that $\sigma_{r 2}$ must be equal to zero.

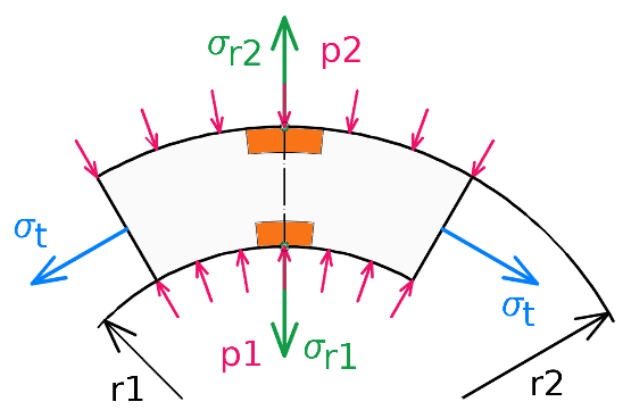

Fig. 2. The stresses in tube.

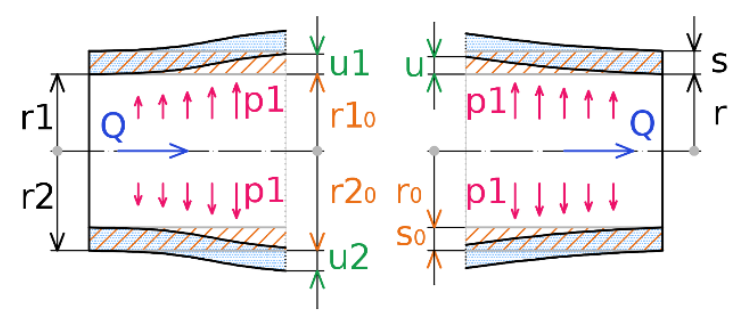

Fig. 3. Loading, dimensions and deformations of the tube.

\subsubsection{Hooke's law}

The relations corresponding to the usual linear Hookean material are also given and used in order to observe the non-linear behavior of the tube material. Using the most general form of Hooke's law for isotropic materials, the radial and circumferential stresses can be defined as (9) and (10) as shown in the Fig. 2. The equation system should be supplemented by an equation of static equilibrium of the thick-walled cylindrical body in the radial direction [13].

$$
\begin{gathered}
\sigma_{r}=\frac{E}{(1+v)(1-2 v)}\left[(1-v) \varepsilon_{r}+v\left(\varepsilon_{t}+\varepsilon_{a}\right)\right] \\
\sigma_{t}=\frac{E}{(1+v)(1-2 v)}\left[(1-v) \varepsilon_{t}+v\left(\varepsilon_{r}+\varepsilon_{a}\right)\right]
\end{gathered}
$$

As the walls of the tube deform, it will also be important to know the displacement in the radial (11), (12) or axial (13) directions. The pipe is fixed at both ends and its length does not change. Therefore it is further assumed that $u_{a}$ is equal to zero, but $\sigma_{a}$ is completely variable. Thus, the equation (13) can further express the axial stress and equally modify and simplify equations (9) and (10).

$$
\begin{aligned}
& u_{1}\left(r_{1}\right)=\frac{r_{1}}{E}\left[\sigma_{t}\left(r_{1}\right)-v\left(\sigma_{r}\left(r_{1}\right)+\sigma_{a}\right)\right] \\
& u_{2}\left(r_{2}\right)=\frac{r_{2}}{E}\left[\sigma_{t}\left(r_{2}\right)-v\left(\sigma_{r}\left(r_{2}\right)+\sigma_{a}\right)\right]
\end{aligned}
$$




$$
u_{a}(L)=\frac{L}{E}\left[\sigma_{a}-v\left(\sigma_{t}(r)+\sigma_{r}(r)\right)\right]=0
$$

To determine the radial stress $\sigma_{r}$ and the circumferential stress $\sigma_{t}$, it is also necessary to determine the corresponding strains in (14).

$$
\varepsilon_{r}=\frac{\partial u}{\partial r} \quad \varepsilon_{t}=\frac{u}{r}
$$

On the basis of the above-mentioned and primarily the relationship (8), it is possible to subsequently define a corrected bulk modulus $K c$ for a thick-walled tube in (15).

$$
K_{C}=\frac{K}{1+\frac{2 K}{E}\left(\frac{r_{1}^{2}+r_{2}^{2}}{r_{2}^{2}-r_{1}^{2}}+v\right)}
$$

If the condition (16) applies, previous relationships can be further simplified and the tube considered as a thinwalled body. However, the test tube does not meet the condition $\{=1.28\}$.

$$
\frac{D^{2}+(D+2 s)^{2}}{2 D^{2}} \leq 1.1
$$

In this case, the relationship for the circumferential stress takes on well-known formula in (17). Correspondingly, $K c$ can also be modified for the thinwalled tube. The radial stresses $\sigma_{r}$ are approximately equal to zero.

$$
\sigma_{t}=\frac{p_{1} D}{2 s}
$$

The tube material is considered as incompressible. In this case, the differential of the tube volume $d V$ must be equal to zero. It should be possible to define the change in wall thickness of the thin-walled tube according to (18), provided that the tube is shortened and stretched. Deformations in transverse directions result from Hooke's law and the axial stresses are equal to zero.

$$
\frac{\partial s}{\partial t}=\frac{D}{2 E(D+2 s)}[D(v-1)+s v] \frac{\partial p_{1}}{\partial t}
$$

However, if the length of the tube $L$ is unchanging, equation (18) takes the form of (19) using the modified equation (13) and assuming $d V=0$.

$$
\frac{\partial s}{\partial t}=\frac{-D^{2}}{2 E(D+2 s)}\left(1-v^{2}\right) \frac{\partial p_{1}}{\partial t}
$$

\subsubsection{Neo-Hookean solid}

One of the material models that allows large deformations of the tube walls is the nonlinear neo-Hookean. This material model proposed by Ronald Rivlin is used for materials based on rubber and plastics. However, with large deformations of the loaded body, it fails and is partially acceptable for deformations smaller than $20 \%$ [14]. Other references assume up to $40 \%$ [15]. From our point of view, it will be important how the stresses, stretch ratios and engineering strains are defined. Since engineering strain is more often used, the equation (20) is related to the stretch ratio. Relationships (22) and (23) provide correlation between radial, circumferential and axial stresses if we consider the incompressible material defined by condition (21). The corresponding $\varepsilon_{r}$ and $\varepsilon_{t}$ are defined by (14).

$$
\begin{gathered}
\varepsilon=\lambda-1 \\
\lambda_{r} \lambda_{t} \lambda_{a}=1 \\
\sigma_{r}-\sigma_{a}=2 C_{12}\left(\lambda_{r}^{2}-\lambda_{a}^{2}\right) \\
\sigma_{t}-\sigma_{a}=2 C_{12}\left(\lambda_{t}^{2}-\lambda_{a}^{2}\right)
\end{gathered}
$$

Equation (22) will be considered for radial stress on the inner and outer surface of the tube provided that $\sigma_{r l}=$ $-p_{1}$. The static pressure $p_{l}$ represents the relative pressure of the fluid to the atmospheric pressure. We also assume that the axial stresses $\sigma_{a}$ at the half of the tube length are equal to its outer and inner radii. The material of the tube is considered as incompressible. Since the tube is firmly fixed at its both ends, its length cannot be changed, as has already been mentioned. Stretch ratio $\lambda_{a}=1$. Therefore, with respect to (14) and (20), there are clear relations between $\lambda \mathrm{r}$ and $\lambda \mathrm{t}$, see (24).

$$
\lambda_{r}=\frac{1}{1+\frac{u}{r}}
$$

However, the axial stress $\sigma_{a}$ varies and depends on the other stresses and deformations of the tube. For unloaded tube, in simulations, at $t=0, \sigma_{a}=0$ is considered, and the tube is not preloaded. Although it should be noted that during the experimental testing the tube was slightly tensioned in the axial direction.

The relationship between the deformation of the tube and the stress caused by the fluid can be expressed explicitly from the equation (22), considering the abovementioned assumptions. In terms of the numerical solution of the system of equations using (6) and (7) it is better to describe the change of inner radius of the tube by (25).

$$
\frac{\partial r_{1}}{\partial t}=\frac{\frac{\partial p_{1}}{\partial t}}{4 r_{1} C_{12}\left(\frac{r_{10}^{2}}{r_{1}^{4}}-\frac{r_{20}^{2}}{r_{2}^{4}}\right)}
$$

Equation (25) is directly based on the loading stresses $\sigma_{r 1}$ and $\sigma_{r 2}$ and therefore (25) from the tested options seems to be the most appropriate. Furthermore, in relation to the equations (6), (7), (24) and (25) it is necessary to add that the condition of the incompressible material and $\lambda a=1$ directly defines the size of the outer radius $r_{2}$ 
depending on the change of radius $r_{l}$. From there using (22) and (23) to obtain the stresses on the outer surface of the tube seems appropriate. We assume, of course, that $\sigma_{r l}$ can be determined or is the result of the interaction between the fluid and the inner wall and $\sigma_{r 2}$ is known from the definition of the task.

The $K c$ modulus for the neo-Hookean solid takes the form (26) and we get it from (8) and (22) if we assume that the stress $\sigma_{a}$ on the outer and inner surfaces is far enough from the ends of the tube the same.

$$
K_{C}=\frac{K}{1+\frac{K}{2 r_{1}^{2} C_{12}\left(\frac{r_{10}^{2}}{r_{1}^{4}}-\frac{r_{20}^{2}}{r_{2}^{4}}\right)}}
$$

If the thickness of the tube wall is very small relative to its radius, we could further simplify this case. Similarly to Hookean solid we will consider that the circumferential stress $\sigma_{t}$ is unchanging in the thin tube wall and is defined as in (17). Previous relationships (25) and (26) will take the form of equations (27) and (28).

$$
\begin{aligned}
& \frac{\partial r}{\partial t}=\frac{r \frac{\partial p_{1}}{\partial t}}{4 C_{12} s\left(\frac{r}{r_{0}^{2}}+\frac{r_{0}^{2}}{r^{3}}\right)-2 p_{1}} \\
& K_{C}=\frac{K}{1+\frac{K}{2 C_{12} s\left(\frac{r}{r_{0}^{2}}+\frac{r_{0}^{2}}{r^{3}}\right)-p_{1}}}
\end{aligned}
$$

\subsubsection{Mooney-Rivlin solid}

The imperfections of the neo-Hookean model that are occasionally mentioned may in some cases remove the more non-linear Mooney-Rivlin model. An analogous sequence of equations from the previous part will be used to describe the material model. The tube material will also be considered as incompressible, see (21). The tube is fixed at both ends and the stresses on the tube walls are defined by the equations (29) and (30).

$$
\begin{aligned}
& \sigma_{r}-\sigma_{a}=2 C_{1}\left(\lambda_{r}^{2}-\lambda_{a}^{2}\right)-2 C_{2}\left(\frac{1}{\lambda_{r}^{2}}-\frac{1}{\lambda_{a}^{2}}\right) \\
& \sigma_{t}-\sigma_{a}=2 C_{1}\left(\lambda_{t}^{2}-\lambda_{a}^{2}\right)-2 C_{2}\left(\frac{1}{\lambda_{t}^{2}}-\frac{1}{\lambda_{a}^{2}}\right)
\end{aligned}
$$

Using the same procedure as the Neo-Hookean solid, the dependence between the change of tube radius $r_{l}$ and the static pressure $p_{1}$ can be obtained, see (31). The corrected modulus $K c$ is then defined in the equation (32).

If we again assume a constant distribution of the circumferential stress $\sigma_{t}$ in the tube wall, we can reformulate the equation (31) to (33) that is formally identical to (27). For the same type of tube material, of course, the relation (34) applies.

$$
\frac{\partial r_{1}}{\partial t}=\frac{\frac{\partial p_{1}}{\partial t}}{4 r_{1}\left[C_{1}\left(\frac{r_{10}^{2}}{r_{1}^{4}}-\frac{r_{20}^{2}}{r_{2}^{4}}\right)+C_{2}\left(\frac{1}{r_{10}^{2}}-\frac{1}{r_{20}^{2}}\right)\right]}
$$

$$
\begin{aligned}
& K_{C}=\frac{K}{1+\frac{K}{2 r_{1}^{2}\left[C_{1}\left(\frac{r_{10}^{2}}{r_{1}^{4}}-\frac{r_{20}^{2}}{r_{2}^{4}}\right)+C_{2}\left(\frac{1}{r_{10}^{2}}-\frac{1}{r_{20}^{2}}\right)\right]}} \\
& \frac{\partial r}{\partial t}=\frac{r \frac{\partial p_{1}}{\partial t}}{4\left(C_{1}+C_{2}\right) s\left(\frac{r}{r_{0}^{2}}+\frac{r_{0}^{2}}{r^{3}}\right)-2 p_{1}} \\
& C_{12}=C_{1}+C_{2}
\end{aligned}
$$

By using equations (28) and (34), we can also describe the relationship for the corrected modulus $\mathrm{Kc}$ in the case of Mooney-Rivlin solid, which is, however, identical to the neo-Hokean formulation (28).

The necessary background data for one-dimensional FSI analysis has now been gathered to compare with experimental testing and FSI ANSYS analysis.

\section{$4 \mathrm{FSI}$ analysis}

The conditions and implementation of FSI simulations are based on experimental testing. The tube was positioned vertically to eliminate its deflection by its own weight. Ovality may cause additional stresses due to the bending moment that is caused by the change in curvature of the tube cross section [16].

Input and output static pressure conditions obtained from pressure sensors are also known. Experimental testing was carried out at Victor Kaplan Department of Fluids Engineering and is described in [17]. Pressure conditions are the main boundary conditions determining the flow regime and subsequent deformations of the tube.

In ANSYS FSI analysis, the tube is fixed at its ends. In one-dimensional FSI analysis, its length does not change during loading and deforms over its entire length. The tube is fixed and slightly axially preloaded in a real experimental testing. Unfortunately, the degree of tube fixation cannot be specified in terms of initiating stress in the tube. However, axial preloading is important for maintaining the straightness of the tube. Neo-Hookean solid was assumed in the ANSYS FSI simulation, which was characterized by the numerical stability of the solution as compared to the Mooney-Rivlin solid.

The boundary conditions, ie static pressures, will be shown in Fig. 4. The first orientation criterion comparing the achieved results is represented by the unsteady volumetric flow rate, which is divided into Fig. 5 and Fig. 
6. The data in Fig. 5 and Fig. 6 can be approximately divided according to whether thin or thick-walled material was considered under the condition (16). N-H FSI simulation was realized only for thick solid, see Tab. 3 . The evaluation of volumetric flow rate, deformations and stresses was carried out at half of the tube length, even with respect to the boundary conditions, even though data are available over entire tube length. Volumetric flow rates are partly influenced by the behavior of the simulated case, which assumes only one-quarter of the tube, and the symmetry conditions in the cut areas (Tab. 1). The original volumetric flow rates obtained from the ANSYS FSI simulations were of course only a quarter. For comparison, the results obtained from the perfectly rigid circular tube under the same pressure conditions are also included in Fig. 5. The symbols used in the figure legend are listed in Tab. 3.

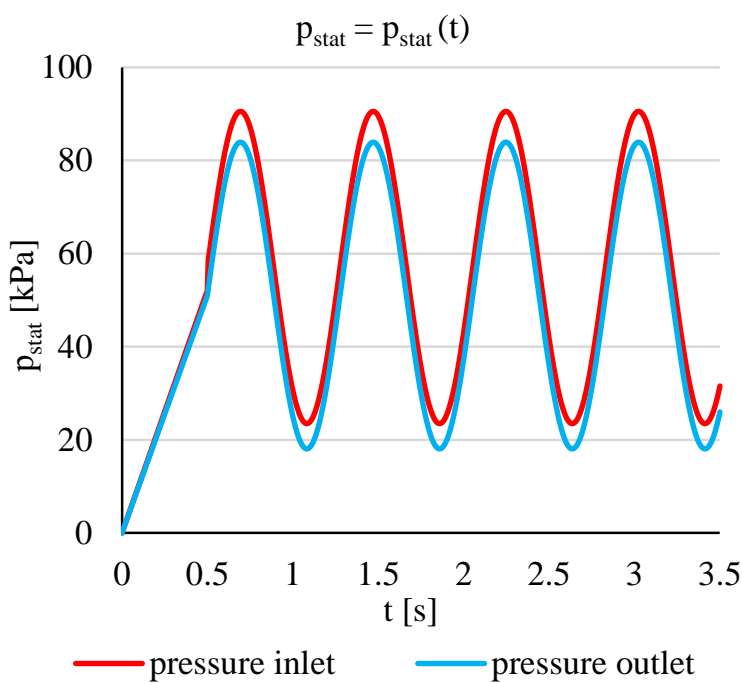

Fig. 4. Pressure boundary condition.

Table 3. Markings used in legend.

\begin{tabular}{|l|l|}
\hline T CFD & 3D CFD simulation in perfectly rigid tube \\
\hline T 1D & $\begin{array}{l}\text { one-dimensional simulation of flow in } \\
\text { perfectly rigid tube }\end{array}$ \\
\hline L 1D & $\begin{array}{l}\text { one-dimensional simulation of flow in } \\
\text { perfectly rigid tube, L - segment, electric } \\
\text { analogy, outlet volumetric flow rate } Q v\end{array}$ \\
\hline N-H FSI & $\begin{array}{l}\text { 3D ANSYS FSI simulation of flexible tube } \\
\text { using neo-Hookean thick solid }\end{array}$ \\
\hline H 1D & $\begin{array}{l}\text { one-dimensional FSI simulation of a } \\
\text { flexible tube using Hookean solid }\end{array}$ \\
\hline N-H 1D & $\begin{array}{l}\text { one-dimensional FSI simulation of a } \\
\text { flexible tube using neo-Hookean solid }\end{array}$ \\
\hline M-R 1D & $\begin{array}{l}\text { one-dimensional FSI simulation of a } \\
\text { flexible tube using Mooney-Rivlin solid }\end{array}$ \\
\hline
\end{tabular}

The data obtained from the CFD simulation for a perfectly rigid tube also verifies the correctness of the implementation of equations (6) and (7) in a onedimensional model. However, the equations (6) may not include differences in the simulation of a perfectly rigid and flexible tube. This is naturally due to differences in velocity and pressure fields in the tube axis and near the moving walls. Therefore, the stationary coefficient of friction $f_{q}$ was increased to 0.052 , which does not correspond to the value $f_{q}$ for a real $R e$ of smooth turbulent flow. The CFD analysis T CFD did not consider the gradual start of the flow. However, in ANSYS FSI analysis the gradual increase of pressure and pressure drop is more advantageous. The one-dimensional analysis does not matter on the above mentioned.

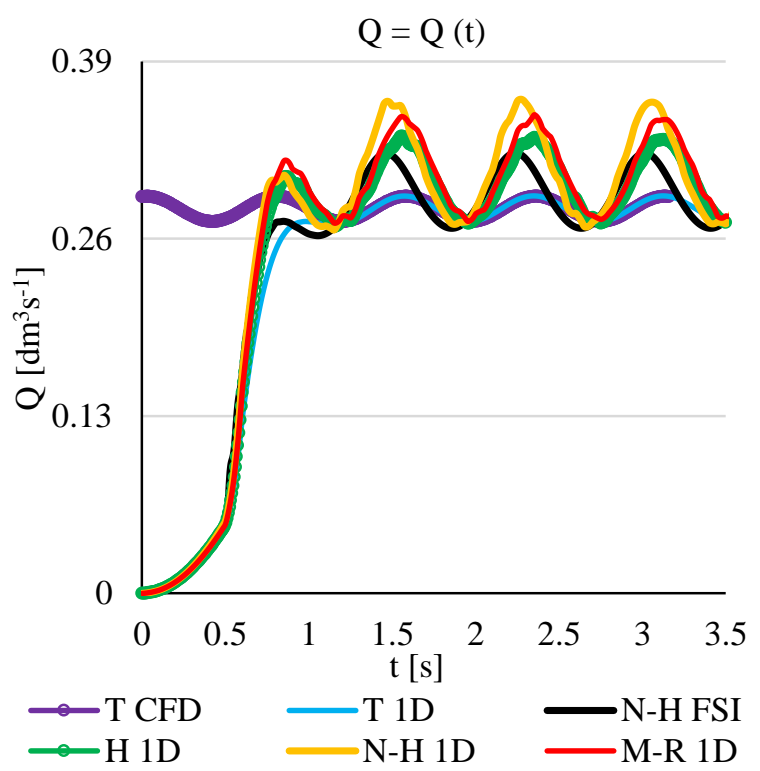

Fig. 5. Volumetric flow rates in the thick-walled tube.

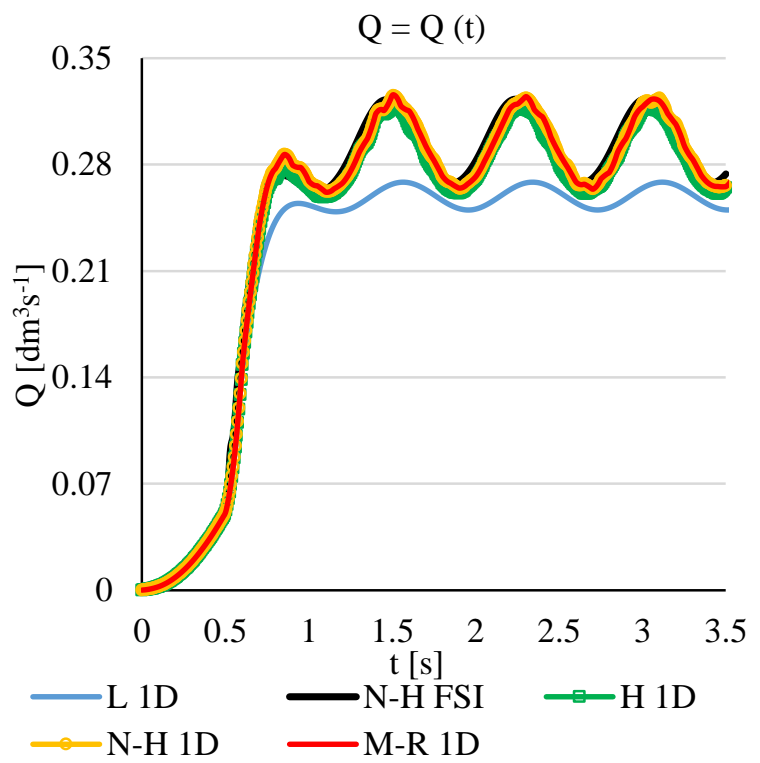

Fig. 6. Volumetric flow rates in the thin-walled tube.

Different maximum volume flow rates compared to the ANSYS FSI simulation achieved primarily in Fig. 5 indicate that the deformation of the tube will be greater in the case of one-dimensional simulations of neo-Hookean and Mooney-Rivlin solid. However, the magnitude of volume flow rate is not essential in terms of the initiation of the tube deformations, since it depends only on the pressures acting on the tube wall. The flow is naturally caused by a pressure drop along the tube length as well as 
deformations of the tube that affect the pressure load. The deformations of the tube determined on the outer diameter of the tube $\mathrm{d} 2$ are shown in Fig. 7 and Fig. 8.

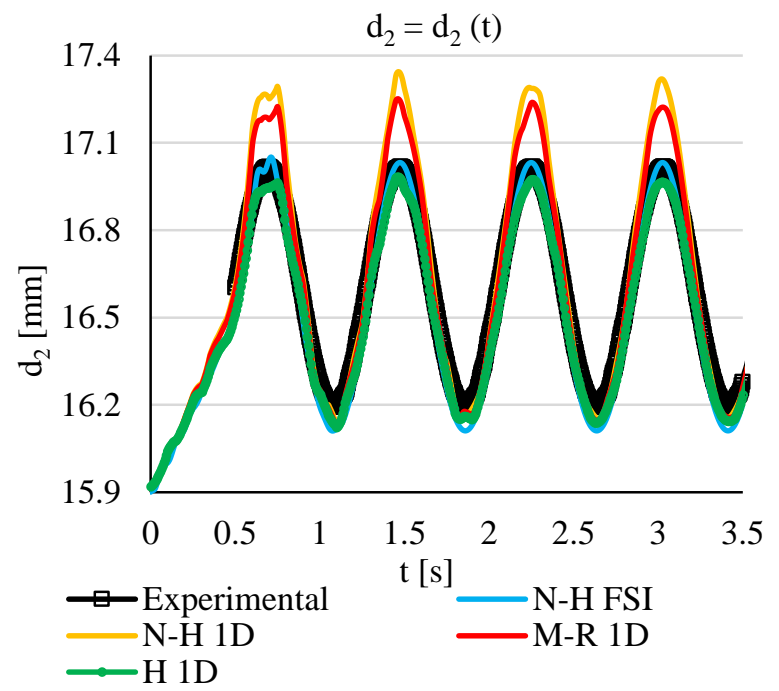

Fig. 7. Outer diameters $d_{2}$ of the thick-walled tube.

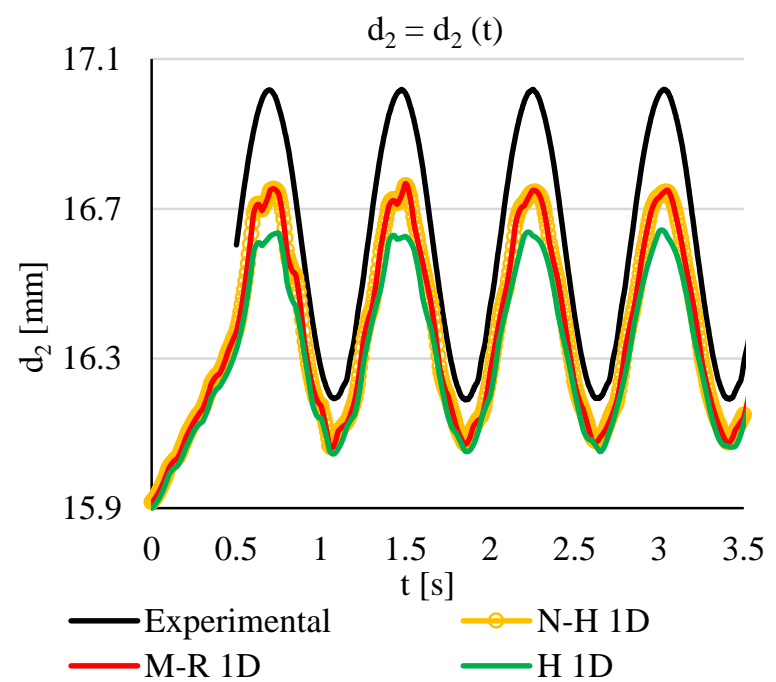

Fig. 8. Outer diameters $d_{2}$ of the thin-walled tube.

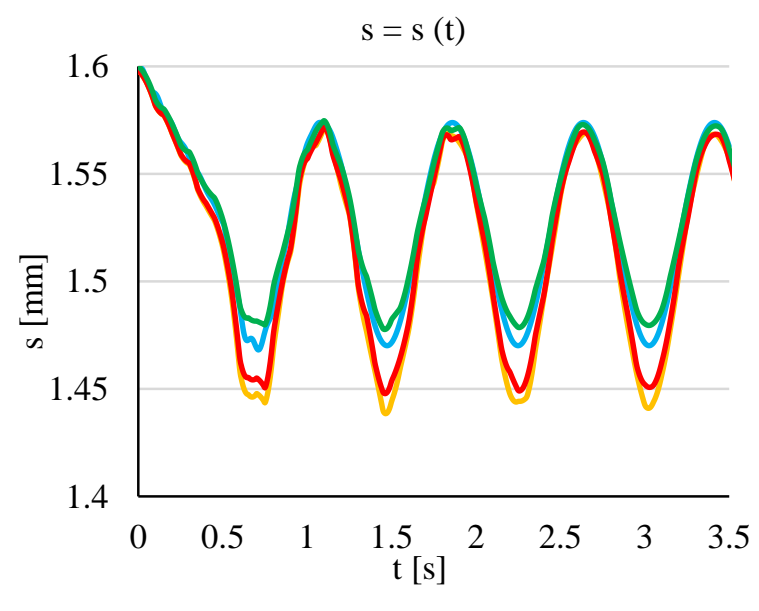

$\longrightarrow \mathrm{N}-\mathrm{H}$ FSI $-\mathrm{N}-\mathrm{H}$ 1D $\longrightarrow \mathrm{M}-\mathrm{R}$ 1D $-\mathrm{H}$ 1D

Fig. 9. Wall thicknesses $s$ of the thick-walled tube.

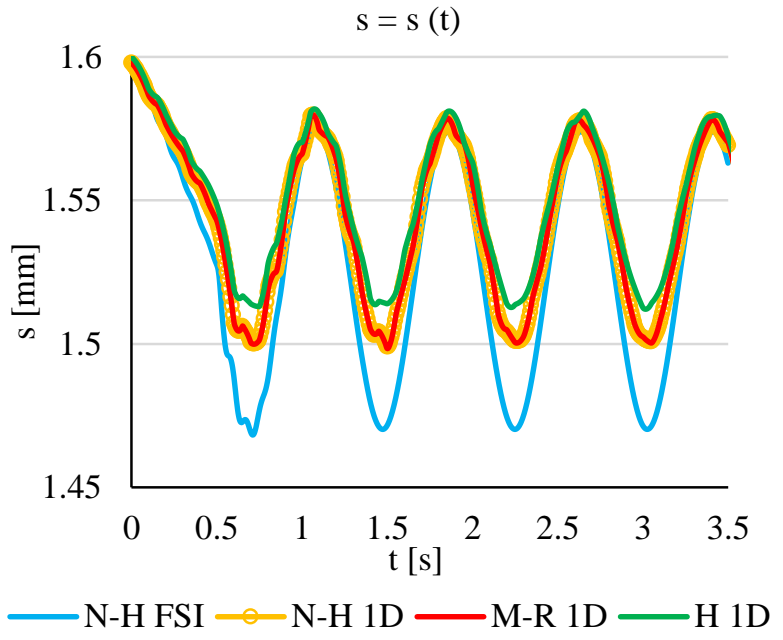

Fig. 10. Wall thicknesses $s$ of the thin-walled tube.

The wall thicknesses of the tube $s$ are shown in Fig. 9 and Fig. 10 instead of the inner diameters of the tube $d_{1}$ $(D, 2 r)$. It may be surprising in the context of Fig. 7 and Fig. 9 that the largest changes in diameter $d_{2}$ and thickness $s$ are represented by the neo-Hookean solid. However, this is due to the fact that the tube is pressure-loaded and, in negative stresses, the neo-Hookean solid shows a greater nonlinear stress-strain relationship than Mooney-Rivlin. The ANSYS FSI simulation has the highest accuracy compared to the experimental testing, followed by a onedimensional model of Hookean material. The reasons explain the following values of radial, circumferential and axial stresses. Indexes 1 and 2 continue to distinguish the outer and inner surfaces of the tube. The static pressures $p$ or radial stresses $\sigma_{r l}$ are presented in the Fig. 11 and Fig. 12. Fig. 13-14 show circumferential stresses $\sigma_{t 1}, \sigma_{t 2}$ and for the thin-walled material $\sigma_{t}$.

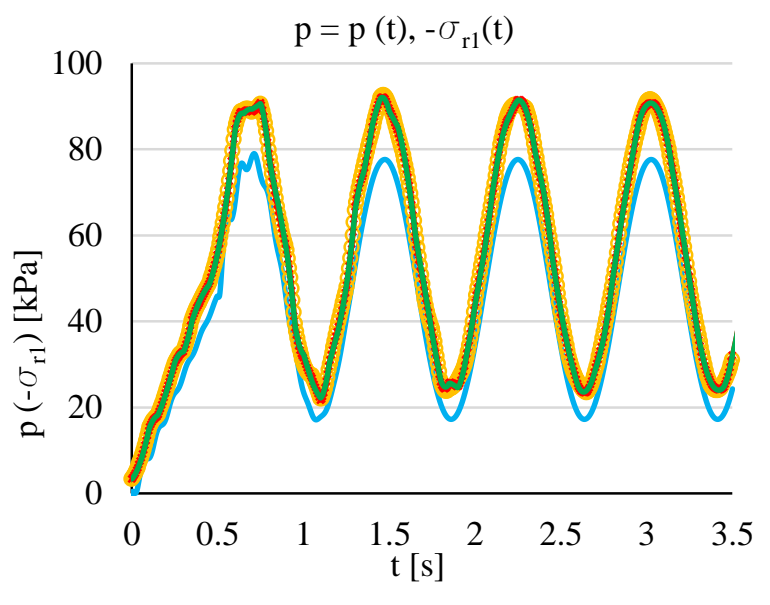

$\longrightarrow \mathrm{N}-\mathrm{H}$ FSI $\multimap \mathrm{N}-\mathrm{H}$ 1D $\longrightarrow \mathrm{M}-\mathrm{R}$ 1D $\longrightarrow \mathrm{H}$ 1D

Fig. 11. Static pressures $p$ in the thick-walled tube.

Fig. 15 and Fig. 16 show axial stresses $\sigma_{a 1}$ a $\sigma_{a 2}$. However, the axial stresses would not differ from the outer and inner tube surfaces. Differences in axial stresses on the outer and inner tube surfaces are minimal in the case of ANSYS FSI simulation and are therefore shown as one stress. There are insignificant differences 
between stresses $\sigma_{a 1}$ and $\sigma_{a 2}$ in the one-dimensional FSI model.

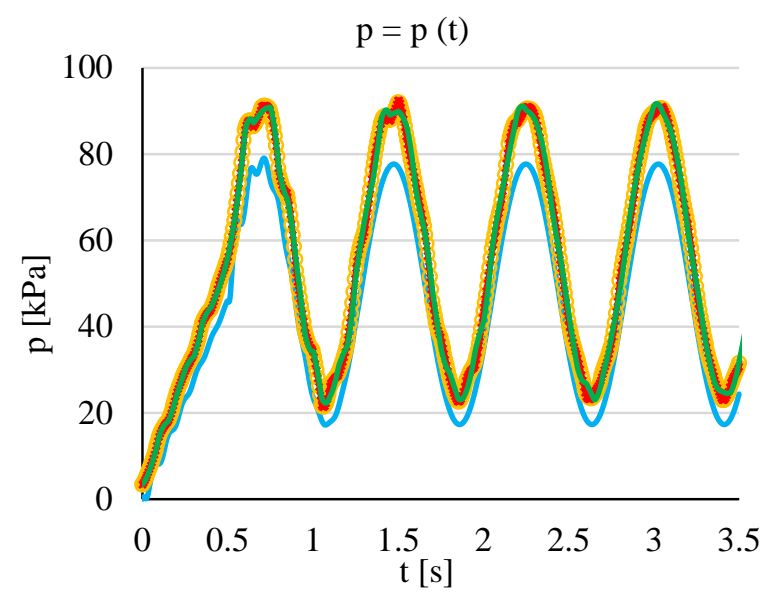

$\longrightarrow$ N-H FSI $-\mathrm{N}-\mathrm{H}$ 1D $\longrightarrow$ M-R 1D $-\mathrm{H}$ 1D

Fig. 12. Static pressures $p$ in the thin-walled tube.

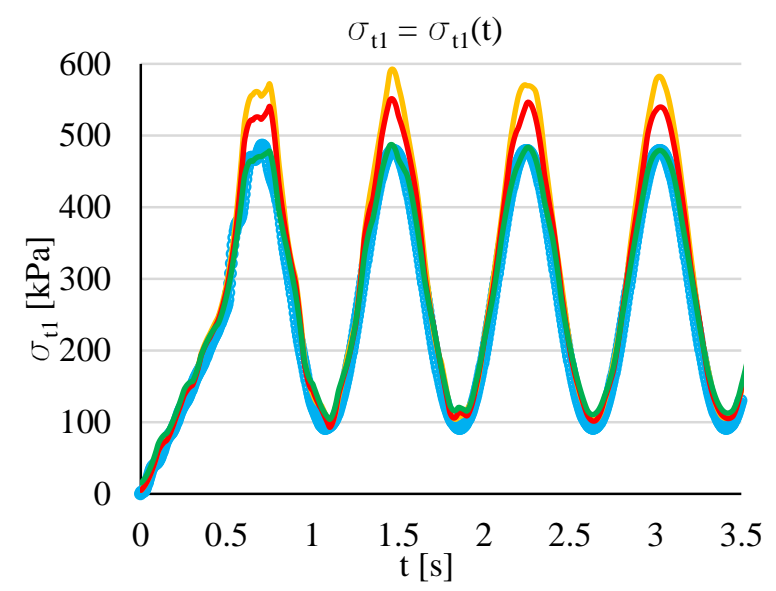

$\longrightarrow \mathrm{N}-\mathrm{H}$ FSI $\longrightarrow \mathrm{N}-\mathrm{H}$ 1D $\longrightarrow$ M-R 1D $\longrightarrow$ H 1D

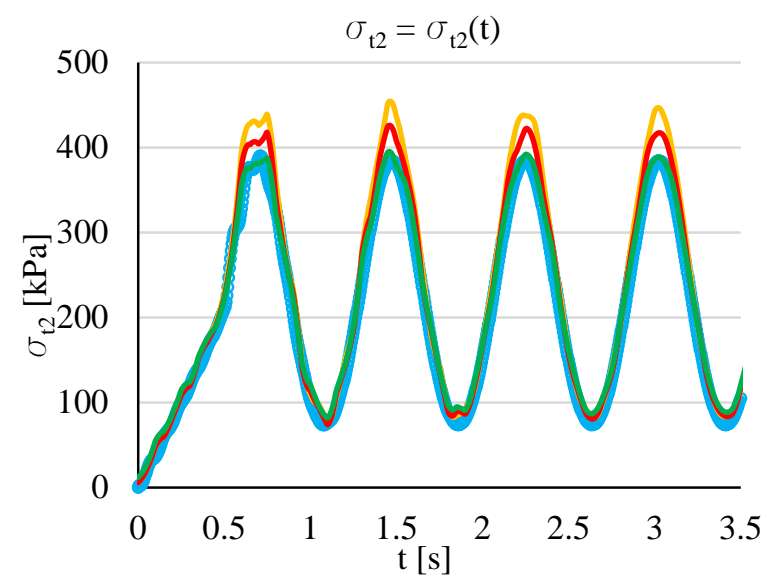

$\longrightarrow \mathrm{N}-\mathrm{H}$ FSI $\longrightarrow \mathrm{N}-\mathrm{H}$ 1D $\longrightarrow$ M-R 1D $\longrightarrow \mathrm{H}$ 1D

Fig. 13. Circumferential stresses $\sigma_{t 1}$ and $\sigma_{t 2}$ in thickwalled tube.

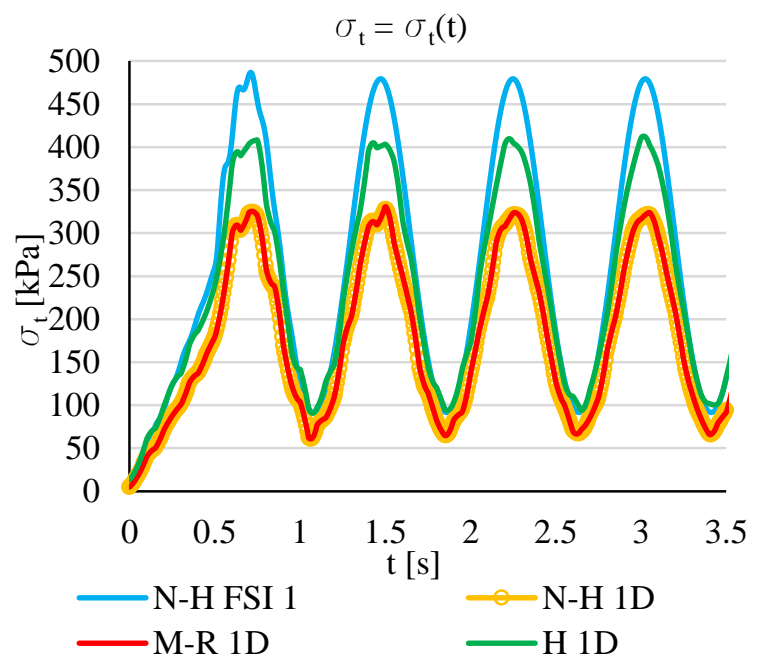

Fig. 14. Circumferential stresses $\sigma_{t}$ in thin-walled tube.

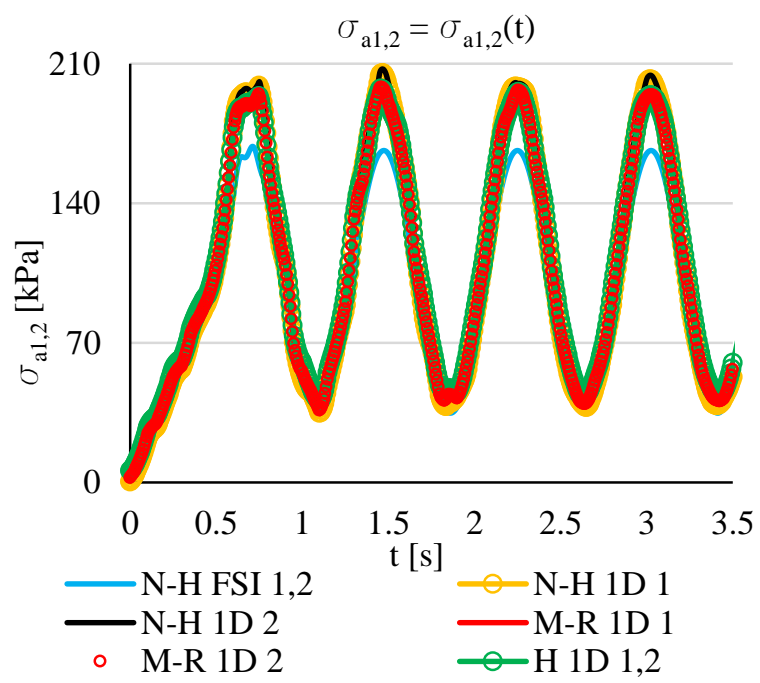

Fig. 15. Axial stresses $\sigma_{a l}$ and $\sigma_{a 2}$ in thick-walled tube.

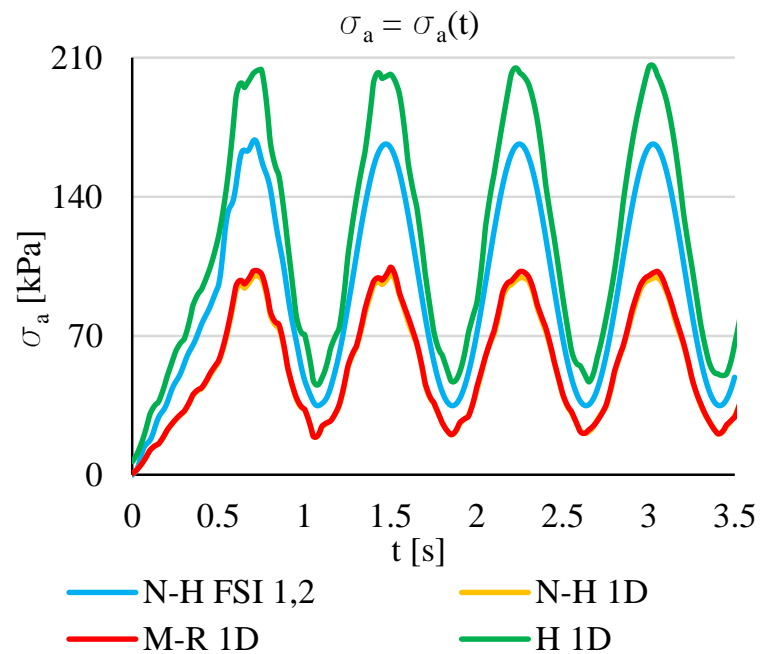

Fig. 16. Axial stresses $\sigma_{a}$ in thin-walled tube.

As it was previously mentioned, the tube deformations depend on the static pressure in the tube. In this context, it is necessary to pay attention to Fig. 11, in which the static pressure at half of the tube length is obtained from 
the ANSYS FSI simulation. If we compare Fig. 11 with Fig. 4 we must note the decrease of the maximum static pressure value compared to the maximum static pressure on the inlet and outlet of the tube. This situation can occur, but from the analysis of the linear case, this condition should become at frequencies higher than the frequencies of the pressures in Fig. 4. The cause of the decrease of static pressure amplitudes shown in the Fig. 11 may be in the case of ANSYS FSI simulation under the boundary conditions by which a quarter of the tube has been fitted, see Tab. 1. It should also be remembered that the tube does not deform at its ends compared to one-dimensional simulations. Conformity of ANSYS FSI simulation of neo-Hookean material with experimental testing may therefore be only incidental, but this is of course not a software problem. However, the degree of fixation of the experimentally tested tube cannot be retrospectively determined.

The question is why the data from experimental testing with ANSYS FSI simulation corresponds, although the agreement is not perfect in the lower displacements of the outer diameter $d_{2}$. There are two probable explanations. The cross section of the tube was not always completely circular, causing additional stress due to ovality. And the second option lies essentially with the Tygon material itself, which in fact does not have such a pronounced non-linear character as it was considered. In this context, it is also necessary to mention the general recommendation to simulate the Tygon material as a Mooney-Rivlin solid. The ANSYS FSI simulation of neoHookean solid was chosen due to Mooney-Rivlin material convergence difficulties.

Also, the one-dimensional FSI models have some drawbacks, and the most obvious one is to predict the volume flow rate. The volume flow through the tubes can be unnaturally changed by the coefficient $f_{q}$. However, the change in the coefficient within reasonable limits has only a slight effect on static pressures along the tube length. Of course, this corresponds to the character of the mathematical-physical model described in particular in (6). The inlet and outlet of the tube are controlled by the pressures in Fig. 4. Moreover, the tube is very short, $L=$ $0.5 \mathrm{~m}$. The pressure pattern in the tube further depends on the frequency, which is very low in our case (approximately 1Hz). The case appears almost as a static despite the relatively considerable deformation of the tube wall with regard to wavelengths.

Three facts can contribute to a better understanding of the problem. The first will deal with the hydraulic coefficient of friction $f_{q}$, which was formulated for stationary flow. However, the flow in the tube is unsteady. Considering the above, the coefficient $f_{q}$ in (6) by Brunone, Vardy and Vítkovsky [18 - 20] can be replaced by $f_{q u}$, see (35).

$$
\begin{aligned}
& f_{q u}=f_{q}+ \\
& \frac{k D S^{2}}{Q Q}\left(\frac{1}{S} \frac{\partial Q}{\partial t}-\frac{2 Q}{r S} \frac{\partial r}{\partial t}+c \operatorname{sign}(Q) \frac{1}{S} \frac{\partial Q}{\partial x} \mid\right)
\end{aligned}
$$

The other parameters are defined in (36) - (38) and are valid in the interval, $R e=2000-10^{8}$.

$$
\begin{gathered}
k=\frac{\sqrt{C^{*}}}{2} \\
C^{*}=\frac{12.86}{\operatorname{Re}^{\kappa}} \\
\kappa=\log _{10}\left(\frac{15.29}{\operatorname{Re}^{0.0567}}\right)
\end{gathered}
$$

The results of one-dimensional FSI simulations solved for neo-Hokean solid using equations 6), (25), (35), (36), (37) and (38) are presented in Fig. 17.

The second factor to be considered is the influence of convective terms that were neglected in (6) and (7). The speed of sound in the hyperelastic tube is very low, and the omission of the changes in volume flow rate or diameter of the tube along its length can cause significant inaccuracies. Therefore, equations (39) and (40) that modify (6) and (8) are used to further evaluate static pressure and volume flow rate.

$$
\begin{gathered}
\frac{\partial Q}{\partial t}=-\frac{Q}{S} \frac{\partial Q}{\partial x}+\frac{2 Q}{r}\left(1+\frac{Q}{c S}\right) \frac{\partial r}{\partial t}+ \\
\frac{S}{\rho}\left(\rho g-\frac{\partial p_{1}}{\partial x}-\rho \frac{f_{q}}{D} \frac{Q|Q|}{2 S^{2}}\right) \\
K_{C}=\frac{K}{1+\frac{2 K}{r}\left(\frac{\partial p_{1}}{\partial r}\right)^{-1}+\frac{Q}{c S}} \approx \\
1+\frac{K K}{r}\left(\frac{\partial p_{1}}{\partial r}\right)^{-1}
\end{gathered}
$$

The mean flow rate in Fig. 5 is relatively low. Even for a very low speed of sound, according to the provisional estimates of $16-20 \mathrm{~m} \cdot \mathrm{s}^{-1}$, the term $Q / c S$ in the equation (40) is relatively small. Moreover, the influence of this term has been tested in the simulations and its significant impact on the achieved results has not been confirmed within the limits. Equation (40) corresponds (8). The flow rates obtained from equation (39) are shown in Fig. 17. The numbers in brackets in the legend indicate the numbering of the corresponding equations.

The static pressures obtained for steady $f_{q}$ and unsteady $f_{q u}$ are practically identical. Considering what has been said about the equation (40), the same applies to the influence of convective terms on static pressures. Of course, other previously monitored parameters were evaluated, but the differences compared to the use of $f_{q}$ and $f_{q u}$ in the equation (6) proved to be minimal. The combination of (35) and (39) has not yet been accomplished. 


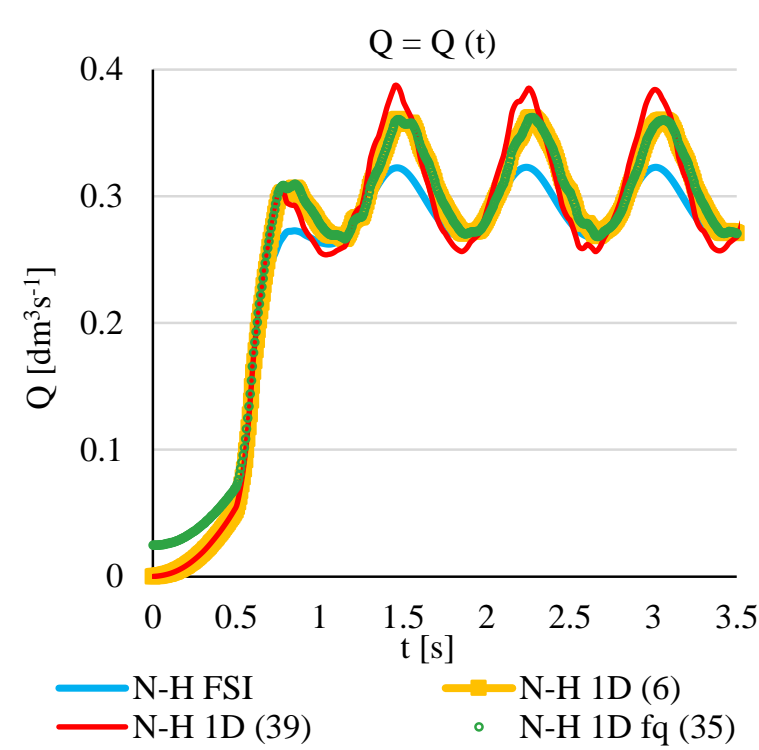

Fig. 17. Volumetric flow rates $Q$ in thick-walled tube.

The initial flow rate cannot be determined as zero with respect to the formulation of the coefficients $C^{*}$ and $\kappa$ in the equations (37) and (38), see Fig. 17. However, if we omit the start of the flow, the consequent consistency between the equation (6) with steady and unsteady friction is relatively considerable. Significant differences occur with the application of the equation (39). But the differences between ANSYS FSI simulation and onedimensional simulation are still enhanced. The modification of input and output conditions of a onedimensional FSI simulation may be another way to understand the correctness of the results. The static pressures in Fig. 4 can be replaced so that the static pressure at the half of the tube length corresponds to the static pressure obtained from the ANSYS FSI simulation in Fig. 11. Consequently, it is possible to compare the tube deformations for both types of simulations by means of variations of diameter $d_{2}$, see Fig. 18. The data obtained from equations of motion (6) and (39) for thick solid are shown in Fig. 18.

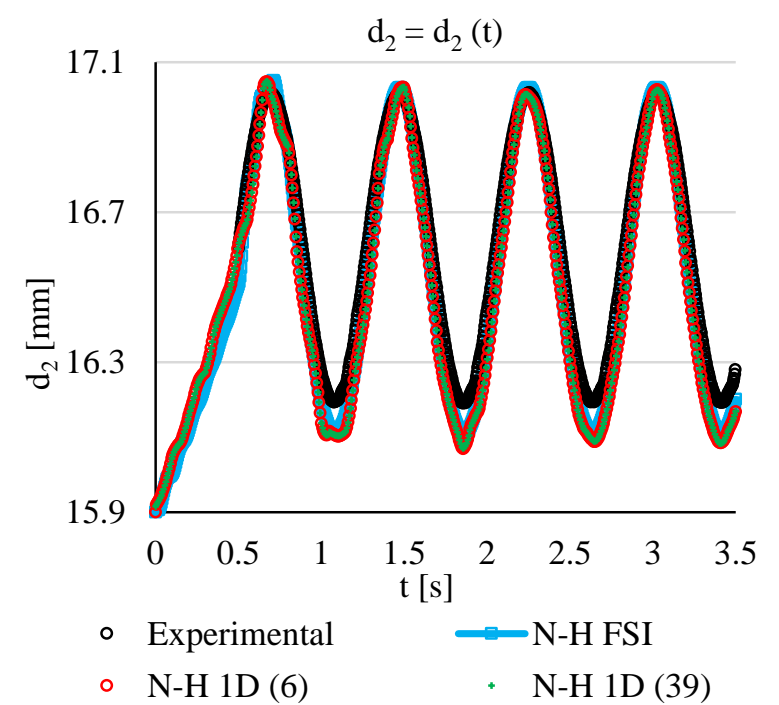

Fig. 18. Diameters $d_{2}$ of thick-walled tube.
As can be seen, the conformity of tube diameters by comparing the one-dimensional and ANSYS FSI simulations is quite significant from this point of view. It follows that the tube deformations can be determined in this case relatively precise and quickly by a onedimensional FSI model. However, a correct determination of the static pressure or volume flow rate in the tube may be difficult.

It is necessary to mention again in connection with the attempt to evaluate the influence of convective terms that the tube is perfectly rigid in the ANSYS FSI simulation at both ends. There are sudden changes in the volumetric flow rate and tube diameter around the tube fixation points, depending on longitudinal coordinate of the tube. This, of course, also affects the stresses in the tube. The tube deformations are locally reduced by fixation, which can be reflected in the magnitude of the axial stress, which is caused by the deformations of the tube, see Fig. 15. The circumferential and tangential stresses depend significantly on the magnitude of the axial stress.

In order to create a better idea of the achieved results, the boundary conditions, which this time form velocity inlet and pressure outlet, were modified. Only a thickwalled body will now be considered. The volume flow rate at the inlet to the tube significantly decreased. The mean volume flow rate is now approximately fifteen times smaller and the volume flow rate is shown in Fig. 20. The influence of some convective terms could be reduced. The static pressure assumed under the pressure outlet condition corresponds to the pressure outlet in Fig. 4. All of the following quantities were again evaluated at half tube length. It is shown in Fig.19 that the volume flow rates are substantially identical for ANSYS FSI and onedimensional FSI simulations. The results obtained through the equations (6) and (39) are shown in Fig. 19. The equation numbering corresponds to the legend. The data in Fig. 19 are very similar.

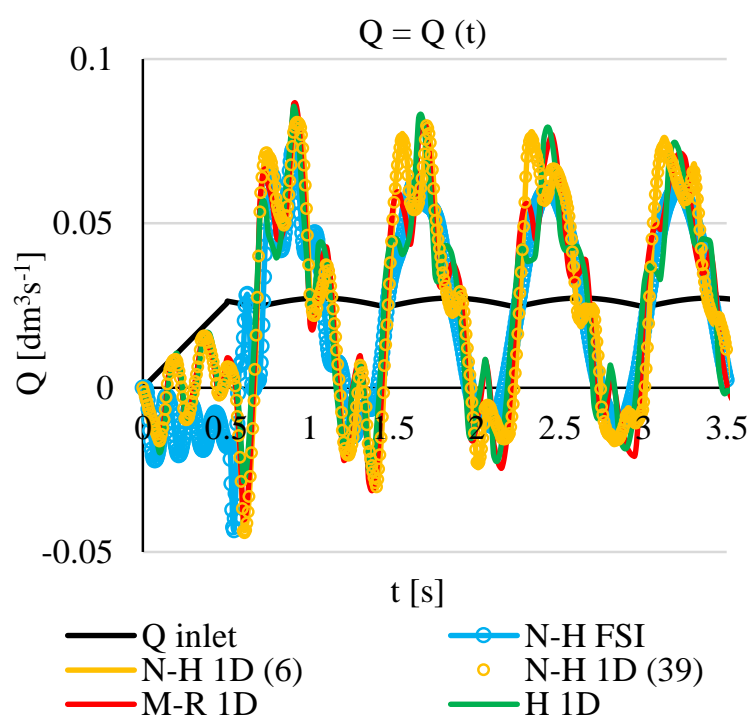

Fig. 19. Volumetric flow rates $Q$ in thick-walled tube. 


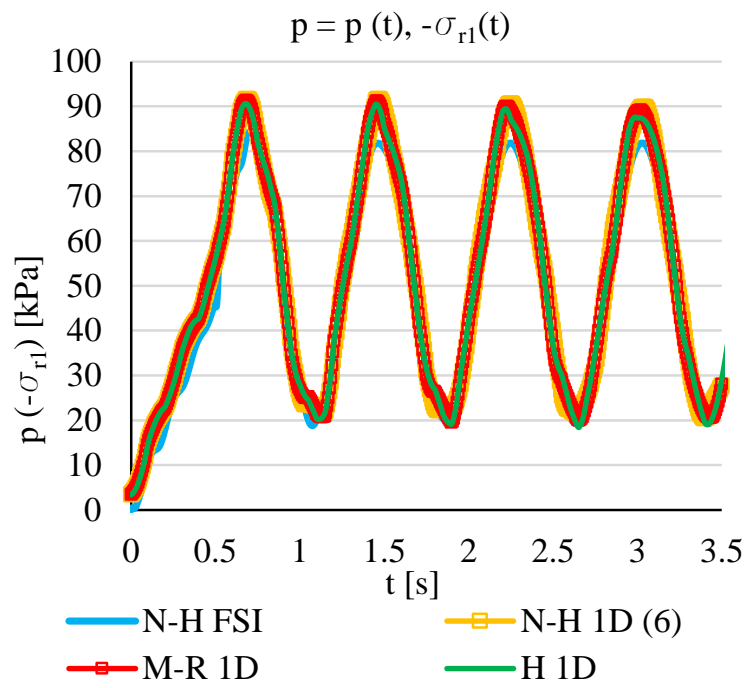

Fig. 20. Static pressures $p$ in thick-walled tube.

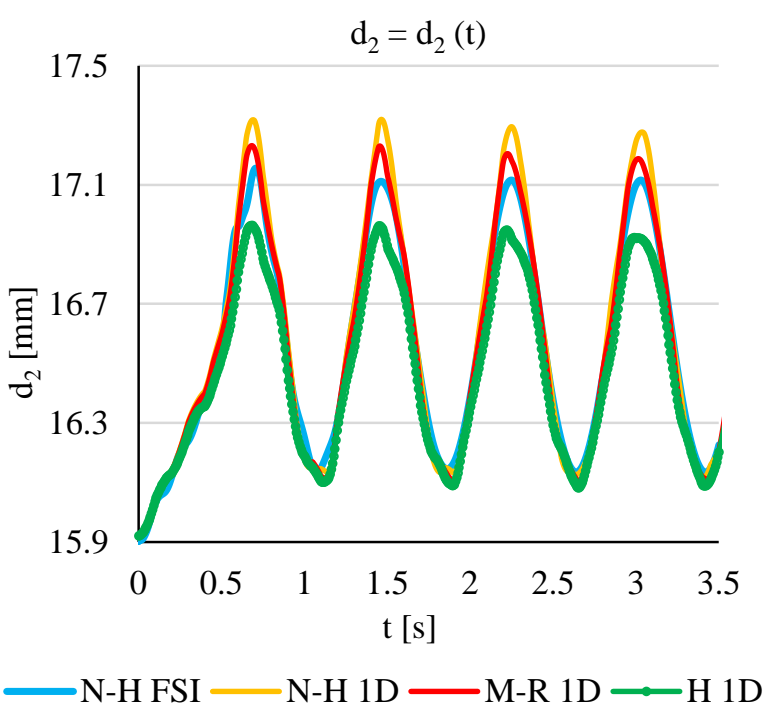

Fig. 21. Outer diameters $d_{2}$ of the thick-walled tube.

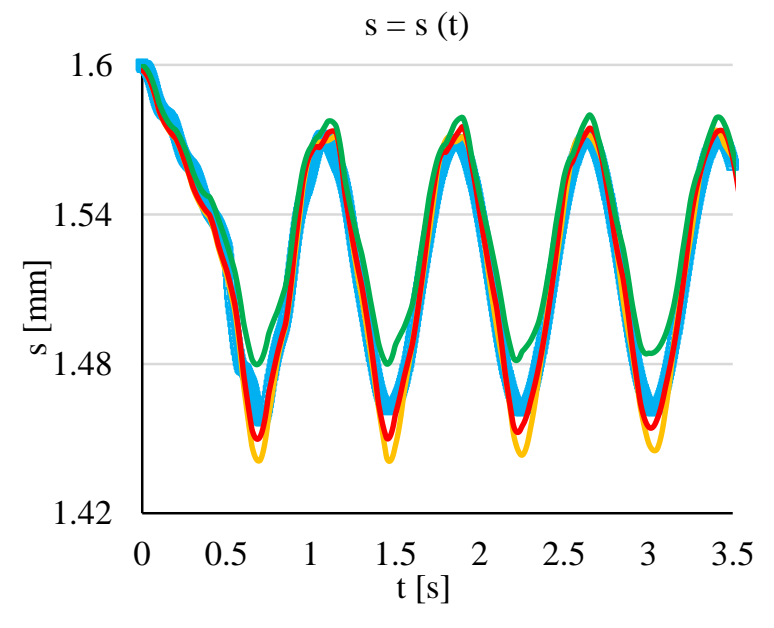

$=\mathrm{N}-\mathrm{H}$ FSI $-\mathrm{N}-\mathrm{H}$ 1D $-\mathrm{M}-\mathrm{R}$ 1D $-\mathrm{H}$ 1D

Fig. 22. Wall thicknesses $s$ of the thick-walled tube.
The results of experimental testing are missing in this case because it would be difficult to obtain a sufficiently accurate time record of the input volume flow rate.

However, the differences between ANSYS FSI and onedimensional simulations remain as can be seen from the following main flow quantities and tube dimensions, see Fig. 20-22. It would be possible to show the stresses in the tube, but we would not reach any qualitatively new results.

\section{Conclusions}

Flow simulations in the flexible tube using different constitutive laws have achieved a relatively accurate conformity with the experimental data regarding the magnitude of the tube deformations. The discrepancies remain in assessing the conformity of the magnitudes of the volume flow rates and static pressures in the tube. The differences between the static pressure on the inner tube surface are shown in all one-dimensional FSI simulations compared to the ANSYS FSI simulation. Differences in static pressure magnitudes are relatively small, but even slight differences have an impact on the deformation of the hyperelastic material. Experimental data cannot be used in this case. The reasons for the differences between 1D and 3D simulations can be found, for example, in different ways of fixing the ends of the tube. The length of the deformed tube can be considered as constant in all cases, but in one-dimensional simulations, the tube cross section is also deformed at the inlet and outlet. The nominal sizes of the circular tube cross sections are stable and independent on the tube static pressures in 3D simulations. Tube was fixed to the ends and even slightly axially preloaded in the case of experimental testing. However, the fixation did not apply to the entire cross section of the tube wall, but only to the outer surfaces. More detailed information about fixation properties and preload magnitudes in terms of specification of the physical mathematical model is missing. However, a new implementation of experimental testing is planned and also a subsequent specification of the boundary conditions of this case in the near future. The fixation properties of the tube affect the magnitude of the axial stress on which the circumferential and radial stresses depend. After all, the axial stress determined by $3 \mathrm{D}$ simulations reaches smaller values compared to $1 \mathrm{D}$ simulations. Axial stress is initiated by changing the size of the tube cross section. The expansion of the cross-sections of the tube at the ends therefore appears to be substantial in view of the incompressibility of the tube material.

Lower static pressure values in the tube, which decrease even below the maximum input and output static pressures, can of course be the natural property of pressure pulsation in the tube for ANSYS FSI simulation. However, due to low frequency and basic linear frequency analysis, the pressure drop would occur at pressure frequencies that are significantly higher than the frequency of pressures in any cross section of the test tube.

Due to the magnitude of the speed of sound in the tube and other parameters, the greater influence of convective terms in the equation of motion and the continuity 
equation appears for higher flow velocities in terms of the prediction of the volume flow rate in the tube. Probably the most fundamental differences between 1D simulations and $3 \mathrm{D}$ simulations can be seen in volumetric flow rates values. It is not always possible to correctly evaluate the volume flow rate even in the case of $3 \mathrm{D}$ simulations, which is probably caused mainly by the boundary conditions and by settings the fluidic part of the FSI simulation. However, the volume flow rate is not critical to the magnitude of the tube deformation. In particular, the pressure in the system affects the deformation of the cross section of the tube. The volume flow rate through the tube is then influenced by the pressure drop magnitude and the cross sectional variation of the tube. The abovementioned tube fixation and tube cross-sectional stability at its ends of course cause sudden changes in tube parameters depending on the longitudinal coordinate and sudden change in volume flow rate. However, convective terms in 1D simulations increase the differences compared to 3D simulations. Equations of motion, even without convective terms, achieve the same results at lower flow rates as 3D simulations.

The problem of one dimensional simulations is also related to the one-dimensional approach itself, which can be affected by the completely different relationship between the pressure magnitudes in the tube axis and near the moving walls. The volume flow rate may change dramatically in the vicinity of the walls due to their movement. These difficulties should be alleviated, for example, by considering unsteady friction in the equation of motion. However, the unsteady friction effects on the flow rate through the tube have only been negligible during the increase in flow and these effects are not observable in the figures. However, it is necessary to say that the unsteady friction was included in the equation of motion in which convective terms were not present.

Also, the thin-walled bodies, which assumed a constant distribution of the circumferential stress in the tube wall, were tested in order to simplify onedimensional simulations. The study shows a well-known standard condition for the use of a think-walled tube defined for Hookean solid, but the test tube does not meet this condition. This fact was reflected in some linear material results. Conversely, the non-linear material in the obtained results predicts smaller differences.

In summary, the obtained results can be evaluated as being quite accurate and at least for a quick orientation in the problem as a benefit due to the considerable time and stability of unsteady 3D FSI simulations. The combination of an equation of motion that does not neglect convective members with unsteady friction in one-dimensional models should be realized in the future. It would also be appropriate to modify the 1D physical mathematical model into a partial 2D model that describes the velocity and pressure field near the moving wall of the tube. Equations describing the deformation of the tube as a function of the static pressure have proven to be sufficiently accurate. This was confirmed in comparison to $1 \mathrm{D}$ simulations with $3 \mathrm{D}$ simulations with consideration of the same static pressure load. On this basis, for example, the velocity of the wall which is in contact with the fluid can be determined.
Grant Agency of Czech Republic, within the project GA101/17$19444 \mathrm{~S}$ is gratefully acknowledged for support of this work.

\section{References}

1. J. B. Grotberg, O. E. Jensen, Annu. Rev. Fluid Mech. 36, pp. $121-147$ (2004)

2. B. S. Brook, T. J. Pedley, J. Biomech. 35, pp. 95 107 (2002)

3. G. Dai, J. P. Gertler, R. D. Kamm, J. Biomech. Eng. 121(6), pp. 557 - 564 (1999)

4. C. D. Bertram, C. J. Raymond, K. S. Butcher, J. Biomech. Eng. 111(3), pp. 185 - 191 (1989)

5. R. S. Rivlin, Phil. Trans. R. Soc. A 240(822), pp. 459 - 490 (1948)

6. R. S. Rivlin, Phil. Trans. R. Soc. A 240(822), pp. 491 - 508 (1948)

7. R. S. Rivlin, Phil. Trans. R. Soc. A 240(823), pp. 509 - 525 (1948)

8. R. S. Rivlin, Phil. Trans. R. Soc. A 241(835), pp. 379 - 397 (1948)

9. M. Mooney, J. Appl. Phys. 11, pp. 582 - 592 (1940)

10. J. G. Hademenos, F. T. Massoud, The Physics of Cerebrovascular Diseases (New York SpringerVerlag, 1998)

11. M. G. Taylor, Phys. Med. Biol. 10(4), pp. 539 - 550 (1965)

12. D. J. Korteweg, Ann. Der Physik und Chemie 5, pp. $525-542(1878)$

13. G. Lamé, B. Clapeyron, Journal für die reine und angewandte Mathematik 7, pp. 381 - 413 (1831)

14. A. N. Gent, Engineering with Rubber (Munich Carl Hanser Verlag 2001)

15. L. A. Mihai, L. Chin, P. A. Janmey, A. Goriely, J. R. Soc. Interface 12:20150486 (2015)

16. D. Ferras, D. I. C. Covas, A. J. Schleiss, J. Fluids and Structure 51, 68 - 84 (2014)

17. D. Šedivý, J. Burša, S. Fialová, Experimental and Numerical Investigation of Flow Field in Flexible Tube, IAHR 2018 (to be published)

18. B. Brunone, U. M. Golia, M. Greco, J. Hydr. Eng. 121(12), pp. 906 - 912 (1995)

19. A. E. Vardy, J. M. B. Braun, J. of Sound and Vibration 259(5), pp. 1011 - 1036 (2003)

20. J. P. Vítkovský, A. Bergant, A. R. Simpson, M. F. Lambert, J. Hydr. Eng. 134(2):284 (2008) 